\title{
A Simulation Magnetic Induction Tomography (MIT) for Agarwood using COMSOL Multiphysics
}

\author{
Nurfarahin Ishak, Chua King Lee, Siti Zarina Mohd Muji
}

\begin{abstract}
Magnetic induction tomography is an imaging technique used to image electromagnetic properties of an object by using the eddy current effect. (MIT) is a non-destructive method that greatly is used in the agriculture industry. This method provided an opportunity to improve the quality of agricultural products. MIT simulation was used for agarwood existence detection. This paper presented for the simulation system contains 7 channel coils receiver and a channel transmitter which is a sensing detector. This experiment aims to demonstrate the reaction of induced current density and magnetic field at 10 $\mathrm{MHz}$ frequency. Then, it also determines the optimal solenoid coil to be used for a better outcome for the magnetic induction system. The simulation result shows that coil diameter, coil length, and coil layer have a crucial role in the great performance of the induced current and magnetic field. The more coil turns, the greater the strength of the permanent magnetic field around the solenoid coil. The result of the simulation is important and needs to be considered to verify the effectiveness of the system for developing the magnetic induction circuit design.
\end{abstract}

Keywords: MIT, relative permittivity, permeability, conductivity, solenoid coil

\section{INTRODUCTION}

A garwood (Aquilaria Malaccensis) is well known as Gaharu in Malaysia and it is also can be found in Southeast Asian Country. This is a species of plant have high valued wood in the market. The agarwood uses for incense, medicine, and perfume for centuries, and in China is widely used for producing carminative, anti-emetic effects, and sedative medication[1][2]. Then, the essential oil was highly demanded as the main ingredient for making luxury perfume[3]. Recently, demand for agarwood is dramatically increasing and agarwood hunters started cutting down to obtain agarwood. To get the matured and quality agarwood needs to wait for the tree to grow and the human experience cannot predict the placement and quantity of agarwood in a tree[4]. The previous researcher used sonic and ultrasonic method to detect the existence of agarwood.

Manuscript received on January 18, 2021.

Revised Manuscript received on February 08, 2021.

Manuscript published on February 28, 2021

*Corresponding author:

Nurfarahin Ishak*, Faculty of Electrical and Electronic Engineering, Universiti Tun Hussein Onn, Johor, Malaysia. Email: farah.ishak25@gmail.com

Chua King Lee, Faculty of Electrical and Electronic Engineering, Universiti Tun Hussein Onn, Johor, Malaysia. Email: chua@uthm.edu.my

Siti Zarina Mohd Muji, Faculty of Electrical and Electronic Engineering, Universiti Tun Hussein Onn, Johor, Malaysia. Email: szarina@uthm.edu.my

(c) The Authors. Published by Blue Eyes Intelligence Engineering and Sciences Publication (BEIESP). This is an open access article under the CC BY-NC-ND license (http://creativecommons.org/licenses/by-nc-nd/4.0/)
This method focusing on the speed of sound[5]. Otherwise, magnetic induction tomography (MIT) was chosen for this experiment. MIT is a non-destructive technique that used an image from the electromagnetic property of an object by using the eddy current effect. MIT applies a magnetic field from the excitation coil to induce eddy currents and the magnetic field is detected by the sensing coil. For example, MIT has been using in medical applications[6][7][8].Usually, $10 \mathrm{MHz}$ frequency widely used in medical application[9] but never apply for agriculture application. So, the $10 \mathrm{MHz}$ frequency is selected because the magnetic field has limited power. Power increases at low frequencies are strongly dependent on the parameters of the coil. In the case of a multi-turn coil, the output power is reduced due to skin and proximity effects[10]. COMSOL multiphysics is used to demonstrate the reaction of the induced current and magnetic field. This demonstration is to investigate theoretical dependence (coil diameter, coil turns and length and coil layers) and the dependence of the magnetic field object on its geometric parameters and the relative magnetic permeability of the samples. These 3 dependence parameters gave a great influence on magnetic strength[11].

\section{MIT COMSOL DESIGN}

Figure 1 shows the design was constructed using COMSOL. The structure of the design consists of a coil as a transmitter and 7 receiver coils. All these solenoid coils hold by the chassis. The test samples are located at the center of the system. The wood sample's measurement is obtained from the real trunk sample while the agarwood measurement was the estimation. This is because agarwood normally is scattered at a different location as in Figure 2. In this paper, it is assumed that agarwood is located at the center of the sample. The assumption of agarwood location was used to differentiate between agarwood and wood reaction on simulation. Then, Figure 3 shows the cutline cross-section for $\mathrm{XZ}$ and $\mathrm{YZ}$ axis. These cutlines are used to get the analysis result. The length for the cutline is $18.6 \mathrm{~cm}$ with the coordinate $(-9.3,9.3)$. The specification for setup diameter of the core wire is $1 \mathrm{~mm}, 2 \mathrm{~cm}$ height of coil, and the coil current is $1 \mathrm{~A}$ at $10 \mathrm{MHz}$ in the COMSOL setting. The other parameter specification setting was in Table 1 . Next, the magnetic specification setup required dielectric properties such as the frequency, relative permittivity, and conductivity. All the dielectric properties values as in Table 2 are used for parameter setup in the COMSOL setting.

Published By:

Blue Eyes Intelligence Engineering and Sciences Publication 
All the values were obtained after undergoes an open-ended coaxial probe experiment method by using Vector Network Analysis (VNA)[12].

The magnetic coils react as a field sensor that has three main concerned parameters: diameter of the coil sensor, coil turns and length and the thickness of the coil turns layer. From these concerns, the induced current density and magnetic field were observed at the agarwood sample. All these parameters were the actual observation affecting the results. So, this process is important to provide an accurate design.

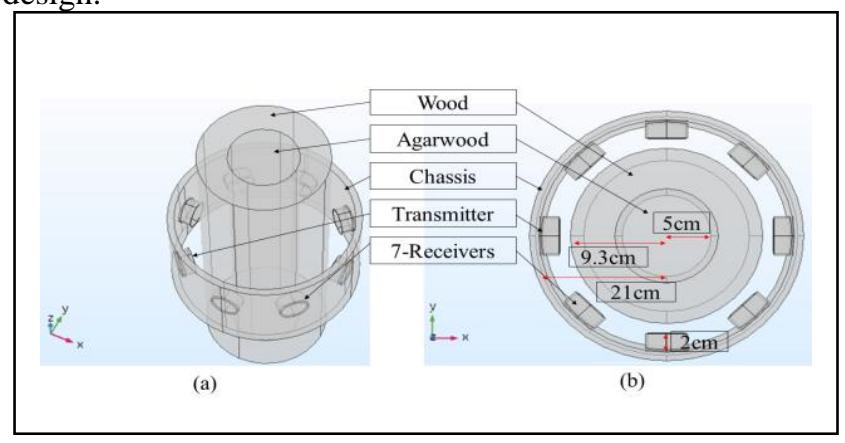

Figure 1: MIT design using COMSOL. (a) View from aside. (b) View from atop

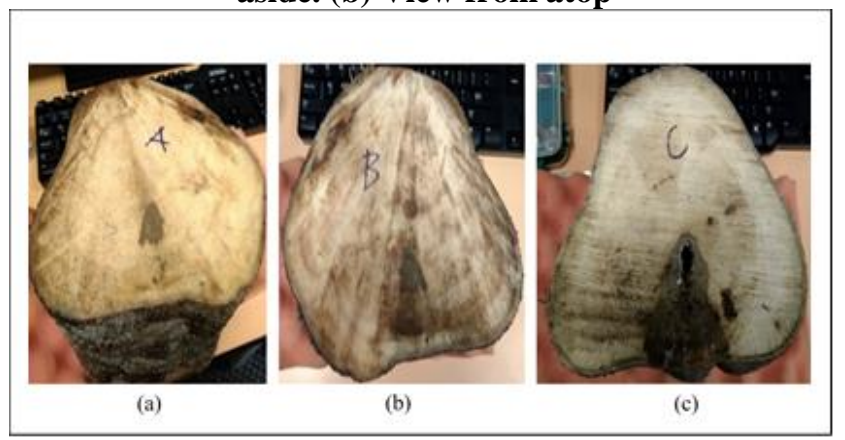

Figure 2: The three differential samples formation size of

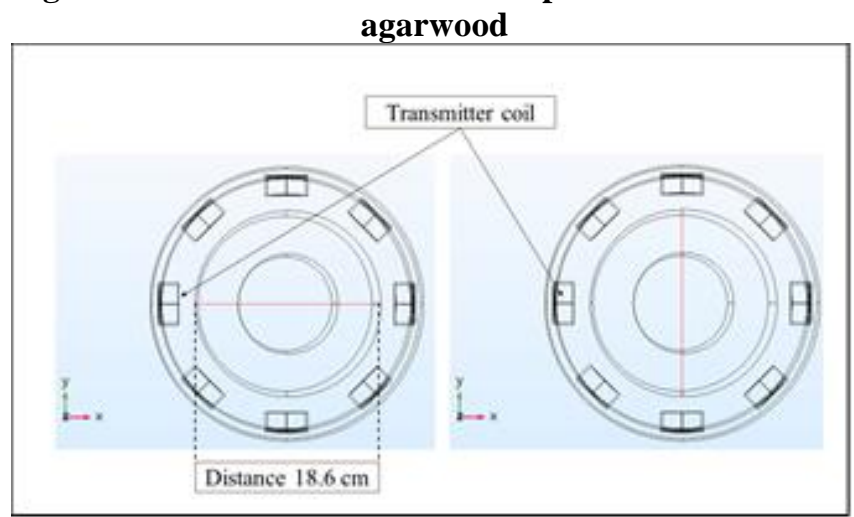

Figure 3: (a) Cutline 1 at XZ- axis and (b) Cutline 2 at YZ- axis cross-section

Table 1: The MIT measurement setup

\begin{tabular}{lcc} 
& Radius $(\mathrm{cm})$ & Height $(\mathrm{cm})$ \\
\hline \hline Chassis & 21 & 25 \\
Wood & 9.3 & 50 \\
Agarwood & 5 & 50 \\
Coils & - & 2 \\
\hline
\end{tabular}

Table 2: The dielectric properties of agarwood at 10MHz[12]

\begin{tabular}{cccc} 
Frequency & Samples & $\begin{array}{c}\text { Relative } \\
\text { Permittivity }\end{array}$ & Conductivity \\
\hline $10 \mathrm{MHz}$ & A & 2.84180 & 0.00219
\end{tabular}

\section{A. Coil Diameter} dielectric value.
0.00870

0.00204

0.00850

\section{SIMULATION AND DISCUSSION}

Coil diameter influences the generation of induced current density and magnetic field. The higher coil diameter has better output performance[11][13]. Figure 4 until Figure 7 showing the induced current density and magnetic field at the YZ-axis and XZ-axis with the different sizes of coil diameter with 10 turns and fixed coil height $2 \mathrm{~cm}$. The diameter coil tested is $4 \mathrm{~cm}$ and $6 \mathrm{~cm}$. Figure 4 referred to the induced current density at XZ-axis while Figure 5 is the induced ent density at YZ-axis. From $0 \mathrm{~cm}$ to $4.3 \mathrm{~cm}$ is the wood section which has a different dielectric value compared to the located. As in the result for the XZ-axis and YZ-axis, the agarwood section and the wood section have different readings. For the result, XZ-axis (Figure 4), the diameter of $4 \mathrm{~cm}$ for all samples started with a high reaction and then fluctuated until it started to flatten. It is opposite with $6 \mathrm{~cm}$ diameter, which rising to high then fluctuated. As in XZ-axis, the diameter of $6 \mathrm{~cm}$ took time for the reaction while $4 \mathrm{~cm}$ gave the fastest reaction. The smaller size diameter showing the better performance, as a result, is $20 \times 10^{-4}\left(\mathrm{~A} / \mathrm{m}^{2}\right)$ compared to the bigger size diameter is $17 \times 10^{-4}\left(\mathrm{~A} / \mathrm{m}^{2}\right)$. Then, for the YZ-axis as in Figure 5 , the $4 \mathrm{~cm}$ diameter shows the high reading compared to the $6 \mathrm{~cm}$ diameter. However, for sample $\mathrm{C}$, the reading is lower than sample A and sample $\mathrm{B}$. This is because the wood structure in the real sample is different from others were contained a hole as in Figure 2. So, it affected the

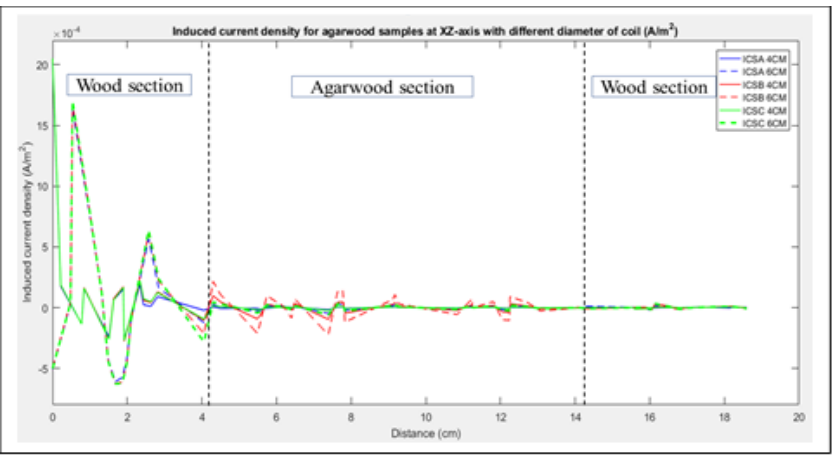

Figure 4: Induced current density at XZ- axis

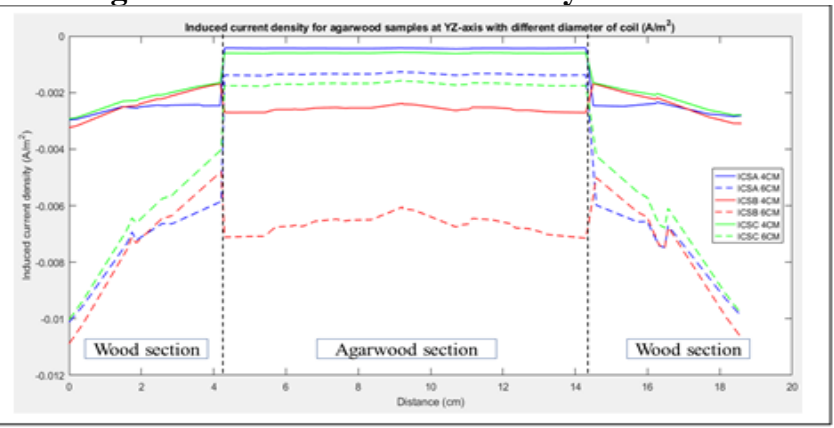

Figure 5: Induced current density YZ-axis 
Addition, in Figure 6 and Figure 7 shows the magnetic field reaction for the different coil diameter. For both figures used the same $\mathrm{x}$-axis coordinate which is $-5 \mathrm{~cm}$ and $0 \mathrm{~cm}$ to observed the magnetic strength using color legend as an indicator. The closest to the coil transmitter, the higher the magnetic field intensity. The $6 \mathrm{~cm}$ diameter coil shows a higher magnetic field than $4 \mathrm{~cm}$ because used longer coil winding. The bigger size diameter used long wire to winding. For example, at $-5 \mathrm{~cm}$ coordinate, $6 \mathrm{~cm}$ shows $20 \mathrm{~A} / \mathrm{m}$ compare to $4 \mathrm{~cm} 10 \mathrm{~A} / \mathrm{m}$.

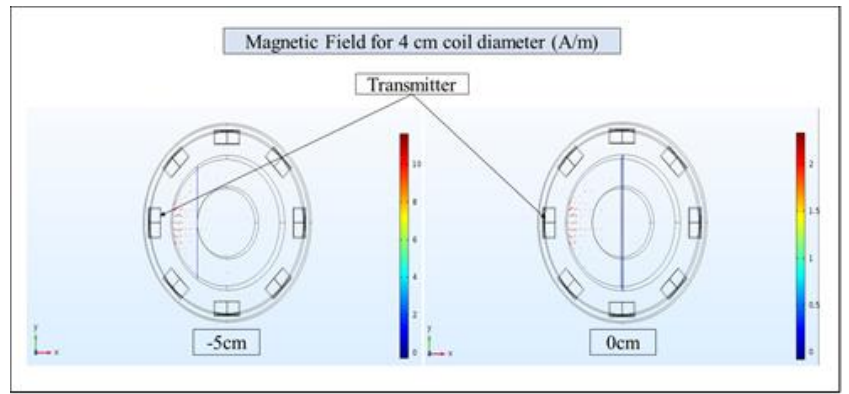

Figure 6: Magnetic field for $4 \mathrm{~cm}$ in diameter

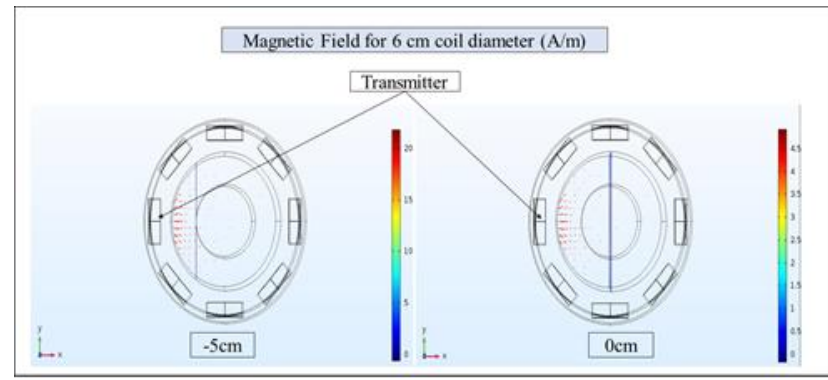

Figure 7: Magnetic field for $6 \mathrm{~cm}$ in diameter

\section{B. Coil turns and length}

From Ampere's Law in equation 1[14], the value of the magnetic field $(B)$ is influenced by the number of turns. The value of $N$ is corresponding to the value of $B$. Figure 8 until Figure 11 shows the effects of changing the number of coils turns. The higher the turns value the greater the induced current and magnetic field. The 10 turns and 20 turns of the coil are used to investigate the changes that happened at the same $2 \mathrm{~cm}$ length of the coil holder and $4 \mathrm{~cm}$ diameter of coils. This experiment was done for the single-layer solenoid.

Magnetic field, $\mathrm{B}=\frac{\mu_{s} \mathrm{IN}}{L}$

$$
\begin{aligned}
& \text { where } \\
& \mu_{0}=4 \pi \times 10^{-7} \mathrm{~T} / \mathrm{amp} \mathrm{m}, \\
& \mathrm{N}=\text { coil turn } \\
& \mathrm{I}=\text { current } \\
& \mathrm{L}=\text { length }
\end{aligned}
$$

Figure 8 shows the induced current density at $\mathrm{XZ}$-axis indicating that it is not much difference between 10 turns and 20 turns. While in Figure 9 clearly shows that there is a double increment. For example, at induced current sample A (ICSA), started with $-3 \mathrm{~A} / \mathrm{m}^{2}$ for 10 turns while $-6 \mathrm{~A} / \mathrm{m}^{2}$ for 20 turns. As a result, observed that 20 turns winding is lower than 10 turns winding. Because the shorter length is generating the close and high magnetic flux. The strength of the field is proportional to the closeness of the lines.

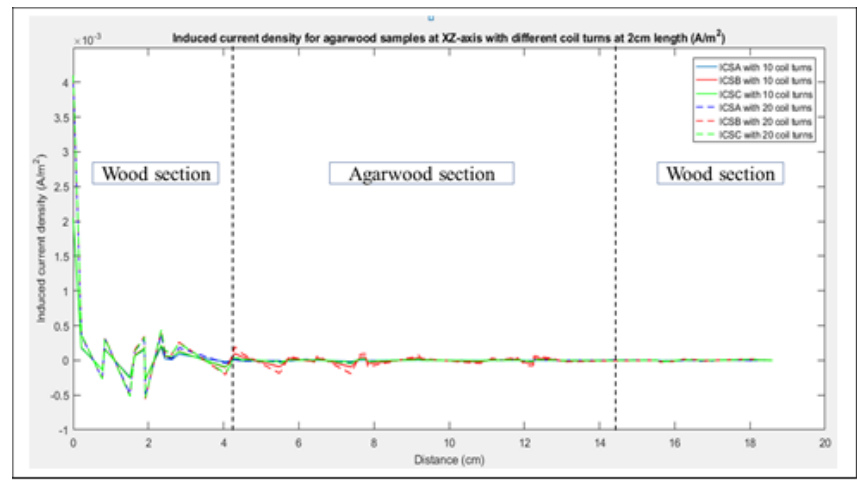

Figure 8: Induced current density at XZ-axis with different coil turns

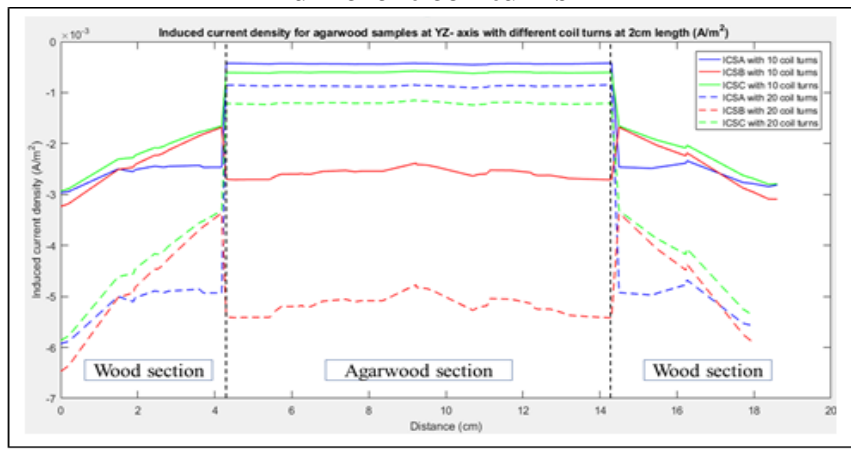

Figure 9: Induced current density at YZ-axis with different coil turns

Figure 10 and Figure 11 show the magnetic field for 10 turns winding and 20 turns winding. The result shows the same level on the color legend as the coil diameter experiment as in Figure 6 and Figure 7. Whereas for the $4 \mathrm{~cm}$ and $6 \mathrm{~cm}$ diameter shows $10 \mathrm{~A} / \mathrm{m}$ and $20 \mathrm{~A} / \mathrm{m}$ while for 10 turns and 20 turns show $10 \mathrm{~A} / \mathrm{m}$ and $20 \mathrm{~A} / \mathrm{m}$ too. The increasing number of coil winding has increased the magnetic field distribution but it's doesn't affect the magnetic field intensity. To increase the magnetic field intensity need to use a multilayer solenoid structure[14].

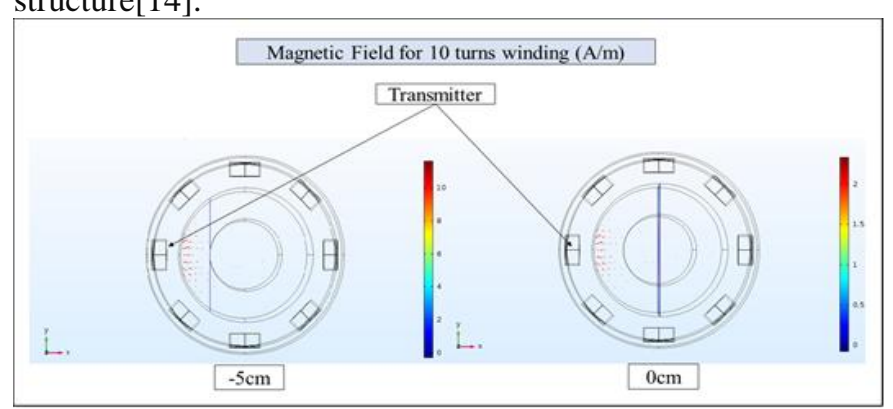

Figure 10: Magnetic field for 10 turns winding

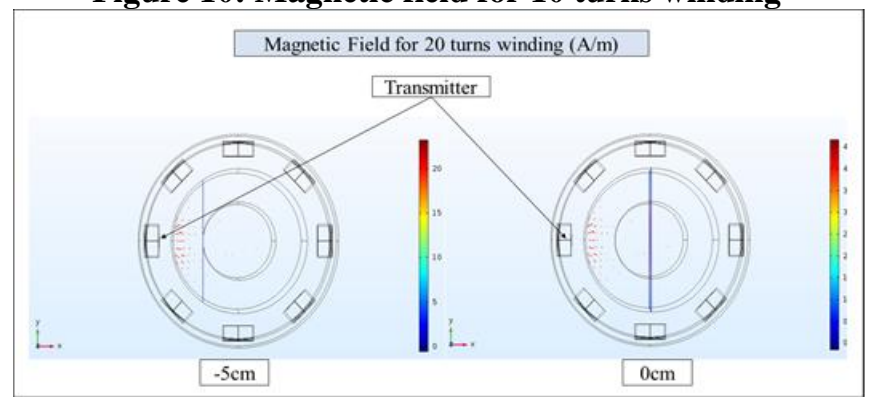

Figure 11: Magnetic field for 20 turns winding

Published By:

Blue Eyes Intelligence Engineering and Sciences Publication

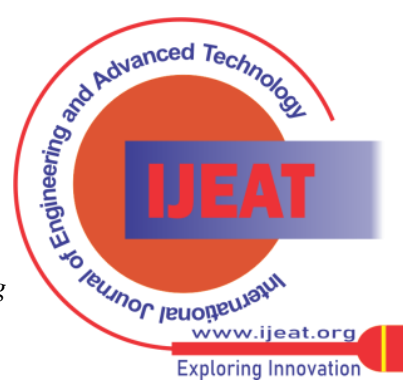




\section{Coil layers}

Coil layers also played a crucial role in magnetic field intensity. Figure 12 until Figure 15 shows the coil layers analysis between 10 turns with a single layer and 50 turns with 5 layers. This section proves that the multilayer coils are a better magnetic field than a single layer. Figure 12 shows that 50 turns 5 layers is higher than 10 turns single layer for XZ-axis. Compare to YZ-axis in Figure 13 shows that 50 turns 5 layers started with high responses then dramatically down and lower than 10 turns single layer. This is because the cutline at YZ-axis was located in the middle of the trunk as in Figure 3(b). The magnetic field produced in the middle or center of the current-carrying solenoid coil is essentially uniform and is focused along the axis of the solenoid coil. The magnetic field becomes much smaller beyond the solenoid coil compare to the XZ-axis the cutline was in the middle of the trunk as in Figure 3(a), the focused along the axis.

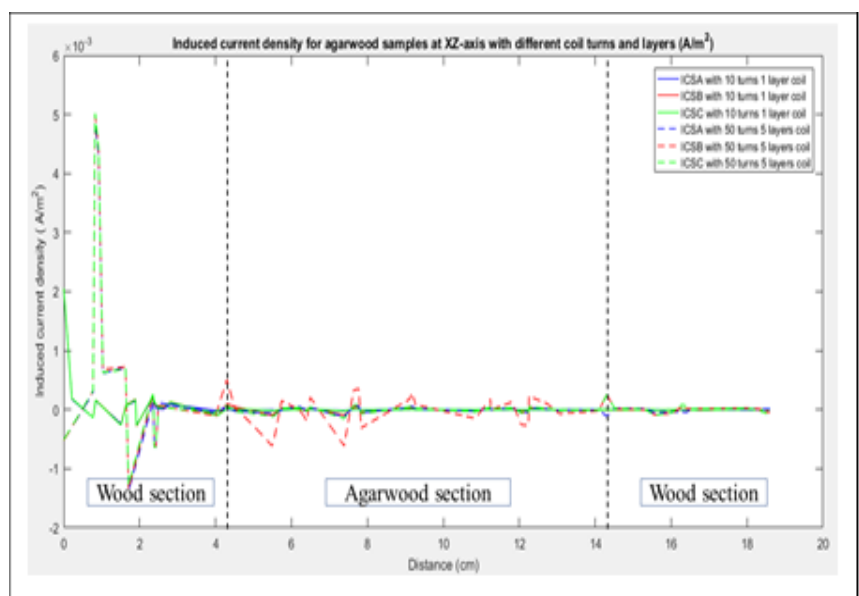

Figure 12: Induced current at XZ-axis with different coil turns and layer

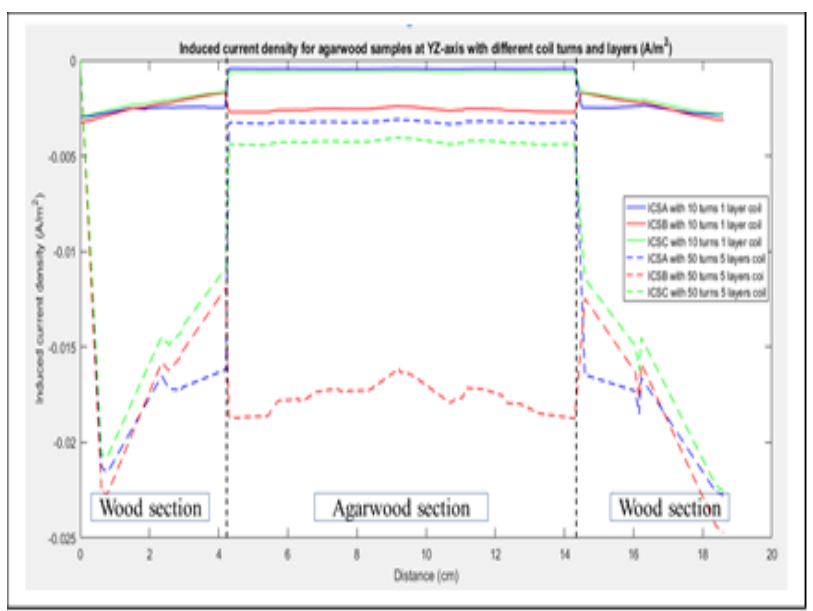

Figure 13: Induced current at YZ-axis with different coil turns and layer

The magnetic field contour map in Figure 14 and Figure 15 shows that the 50 turns 5 layers is higher than 10 turns single layer. For 5 layers shows $60 \mathrm{~A} / \mathrm{m}$ while a single layer shows $10 \mathrm{~A} / \mathrm{m}$. The magnetic induction intensity was depending on the layers of the coil[14]. The larger thickness of solenoid coils, the greater of magnetic field intensity. By use of a multi-layer coil in the electromagnetic forming of big and thick-walled sheets resulting in improved energy output[15].

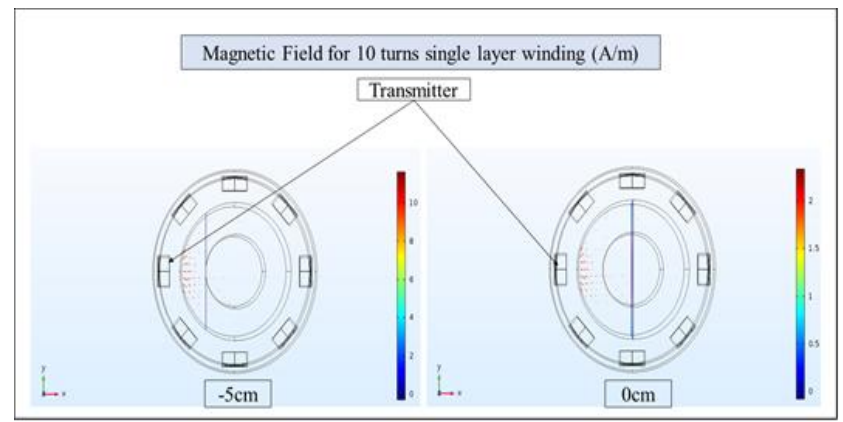

Figure 14: Magnetic field for 10 turns the single layer

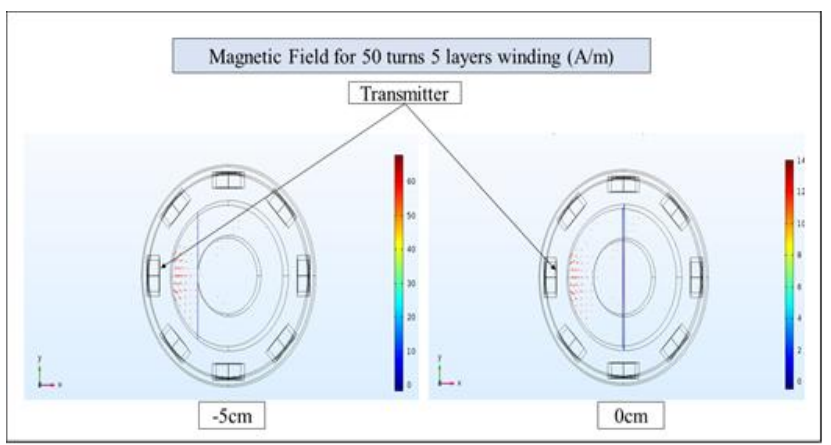

Figure 15: Magnetic field for 50 turns 5 layers

\section{CONCLUSION}

In conclusion, referring to the simulation analysis result found that, MIT can detect the agarwood inside the sample by using $10 \mathrm{MHz}$ frequency which is usually used by the medical-industrial application. The three main concerned parameters: diameter of the coil sensor, coil turns and length and the thickness of the coil turns layer have a good impact on induced current and magnetic field. Small diameter and multi-layer coil are suitable to use for MIT because of the more coil layer, the greater the strength of the permanent magnetic field around the coil. Then the smaller diameter solenoid coils the larger induced current density. Despite this, the conductivity of the sample has to be considered for a more accurate result. This finding can be used as a reference when designing an MIT setup.

\section{ACKNOWLEDGMENTS}

This research was supported by Ministry of Higher Education (MOHE) through Fundamental Research Grant Scheme (FRGS/1/2018/TK04/UTHM/02/28) or Vot No. K087. The authors also would like to dedicate special thanks to Research Management Centre (RMC) of Universiti Tun Hussein Onn Malaysia for its support to achieve the goal of research work.

\section{REFERENCES}

1. X. Chen et al., "Trunk surface agarwood-inducing technique with Rigidoporus vinctus: An efficient novel method for agarwood production," PLoS One, vol. 13, no. 6, pp. 1-13, 2018.

2. Z. Q. Wu et al., "Analysis of gene expression and quality of agarwood using agar-bit in aquilaria sinensis," J. Trop. For. Sci., vol. 29, no. 3, pp. 380-388, 2017.

3. W. K. T. Thomas, M. H. F. Rahiman, and P. J. Soh, "an Initial Study To Investigate the Potential of Microwave Tomography for Agarwood Imaging," Int. J. Agric. For. Plant., vol. 4, pp. 26-32, 2016. 
4. Yap Yee Hwai, Kamaruzaman bin Ali Budin, and Zahari bin Ibrahim, "Panduan Penanaman Karas," in Panduan Penanaman Karas, OMR PRESS Sdn.Bhd, 2010, p. 76.

5. L. Karlinasari, N. Indahsuary, H. T. Kusumo, E. Santoso, M Turjaman, and D. Nandika, "Sonic and ultrasonic waves in agarwood trees (aquilaria microcarpa) inoculated with fusarium solani," J. Trop. For. Sci., vol. 27, no. 3, pp. 351-356, 2015.

6. D. Yang, C. Liu, B. Xu, and X. Wang, "Hardware Design for Magnetic Induction Tomography Imaging System in Biomedical Application," J. Med. Imaging Heal. Informatics, vol. 7, no. 1, pp. 88-93, 2017.

7. N. B. Othman, T. Tsubaki, T. Yoshida, K. Enpuku, and A. Kandori, "Magnetic nanoparticle imaging using harmonic signals," IEEE Trans. Magn., vol. 48, no. 11, pp. 3776-3779, 2012.

8. M. Saiful et al., "Magnetic Induction Tomography Modeling in Biological Tissue Imaging Using Two-Port Network Technique," Sens. Transducers, vol. 150, no. 3, pp. 112-119, 2013.

9. L. Wang, "Three-dimensional holographic electromagnetic imaging for accessing brain stroke," Sensors (Switzerland), vol. 18, no. 11, 2018.

10. Morag and Levron, "Output Power Limit in Energy Harvesting Systems Based on Magnetic Induction Incorporating High-Frequency Effects," Instruments, vol. 3, no. 2, p. 26, 2019.

11. U. C. Inan, "Design and Implementation of Magnetic Field Sensors for Biomedical Applications," 2015.

12. N. Ishak, C. K. Lee, S. Zarina, and M. Muji, "Dielectric properties measurement of Agarwood using Vector Network Analyzer for frequency $200 \mathrm{MHz}$ until $1 \mathrm{GHz}$," in 2nd International Conference on Computer Science, Electrical \& Electronic Engineering 2020, 2020, pp. 1-11.

13. N. A. A. Latif, I. M. Z. Abidin, M. Dollah, and A. Nassir, "A study of effects on size and coil's turns based on signal distribution on impedance plane diagram," 2012.

14. J. Wang, M. Jia, Z. Lv, Y. Liang, and Z. Li, "Analysis of the Magnetic Field in the Cavity of Multi-Layer Winding Electromagnetic Water Processor," IEEE Access, vol. 7, pp. 2512-2519, 2019.

15. W. Luo, L. Huang, J. Li, X. Liu, and Z. Wang, "A novel multi-layer coil for a large and thick-walled component by electromagnetic forming," J. Mater. Process. Technol., vol. 214, no. 11, pp. 2811-2819, 2014.

\section{AUTHORS PROFILE}

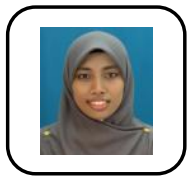

Nurfarahin Ishak was born on 1990 in Perak, Malaysia. She received the Diploma (Electronic Computer Engineering) from Ungku Omar Polytechnic in 2011 and B. Sc. (Electronic Engineering) in 2016 from Universiti Tun Hussein Onn Malaysia. Currently, she is doing M.

Onn Malaysia. Sc (Electrical Engineering) at Universiti Tun Hussein

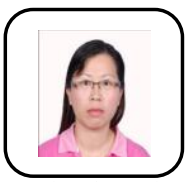

King Lee Chua was born in Sarawak, Malaysia, in 1976. She received the Diploma in Electronic Engineering from the Polytechnic Kuching, Sarawak, Malaysia, in 1997, the Bachelor of Science in Electrical Engineering (Control and Instrumentation) from the Universiti Teknologi Malaysia, Johor, Malaysia, in 2002, the Master of Science in the Universiti Kebangsaan Malaysia, Selangor, Malaysia, in 2005, and the Doctor of Philosophy in Electric Engineering from the Universiti Tun Hussein Onn Malaysia, Johor, Malaysia, in 2015. She has been engaged in research activities with industry in the field of electromagnetic integrity on chip level using GTEM cell and anechoic chamber, other electromagnetic compatibility-related topics. Her research interests include FPGA design, embedded system design and applications, and chip level radiated emission-related topics.

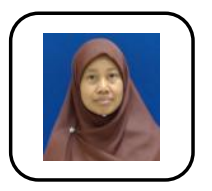

Siti Zarina Mohd Muji was born in Batu Pahat, Malaysia in 1978. She received B. Sc. (Electrical and Electronic Enginnering (Computer)) And M. Sc (Electrical and Electronic Engineering (Data Communication)) from Universiti Sains Malaysia in 2001 and 2004 respectively and the Ph.D. (Electrical Engineering (Electronic Instrumentation)) from Universiti Teknologi Malaysia in 2012. She is a member of the professional membership Board of Engineer (BEM) since 2014. Her research interest is Embedded system and Tomography.

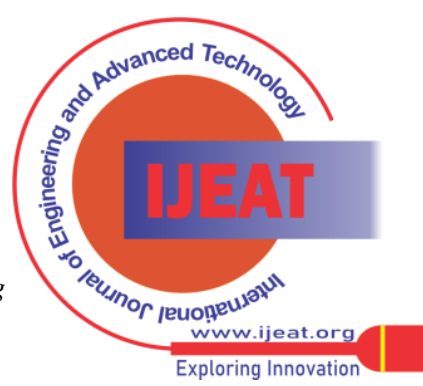

